\title{
The Nature of the Space: Walls to Bridges as Transformative Learning
}

\author{
Anna Sferrazza
}

\begin{abstract}
Community-based learning initiatives have the potential to have a meaningful impact on participants. When integrated into an academic setting, such experiential learning opportunities can initiate transformative learning within students and the broader community. Through a self-reflexive approach, this essay describes one such first-hand experience from a Walls to Bridges class, offered through Wilfrid Laurier University and facilitated in a Canadian Federal Prison. The learning model utilized within this class has the capacity to deeply engage students in ways where traditional classroom methodology falls short. Institutionalized education can learn a great deal from this model, which values diversity and community building, and which centralizes voices that are often absent or marginalized in academic settings. This essay examines the nature of a Walls to Bridges class as it compares to traditional educational experiences. The essay explores current, dominant educational paradigms that are influenced by capitalistic values and can perpetuate power imbalances and systemic barriers, while also highlighting alternatives to traditional education models. Teaching methodologies, such as collaborative rather than competitive learning, circle pedagogy, the creation of a safe classroom space, power redistribution, and creative means of critical classroom discussions, are celebrated as opportunities for deep learning.
\end{abstract}

KEYWORDS Walls to Bridges; incarcerated students; experiential learning; circle pedagogy; institutionalized education

Community-based learning can have deeply transformative effects. Experiencing and witnessing firsthand the realities of what one studies has the power to leave a lasting impression and to challenge one's sense of knowing. I had one such experience during my participation as a non-incarcerated student in a Walls to Bridges class. Walls to Bridges is the Canadian version of Inside-Out, the well-known prison exchange program founded in the United States, where incarcerated and non-incarcerated students take university classes together inside penal institutions. ${ }^{1}$ The Walls to Bridges class in which I was enrolled was offered through the Masters of Social Work program at Wilfrid Laurier University and took place within a Canadian federal prison in Kitchener, Ontario. There were 20 students - 10 incarcerated women and 10 nonincarcerated women — and one facilitator/instructor. Entitled "Race, Gender \& Crime," the class was focused on a range of topics, including punishment, the war on drugs, immigration,

\footnotetext{
${ }^{1}$ The Walls to Bridges program is also discussed in essays by Harris and Davis (both this issue).
} 
the incarceration of transgender people, colonialism and neocolonialism, violence against women, restorative justice, creative responses to injustice, and much more. Amongst all of these multifaceted issues, one that stood out as being particularly relevant to my social location and crucial for me to explore was the complex and challenging nature of institutionalized education. Using a critical self-reflexive approach, this essay will discuss my experience in the Walls to Bridges class and offer a critique of the limitations of institutionalized education. I argue for the necessity of creative, transformational, and inclusive educational spaces where community is built.

Before taking the Walls to Bridges class, I thought of myself as progressive in my political views as well as in my perceptions of institutions. Coming from a conservative Christian upbringing, I was well-versed in challenging institutionalized religion for my own spiritual, physical, and emotional liberation. It was within this context that I began to understand how Christianity has been bound up with the neo-colonial forces of cultural domination and oppression that have left deadly footprints on most of the planet. Through my undergraduate degree in Social Justice and Peace Studies, with a minor in Religious Studies, I began to discern my own path of faith. Discovering liberation theology, which looks at the life of Jesus as an act of resistance that exemplifies solidarity with the marginalized and locates the gospel amidst struggles for social justice, I was able to salvage my faith and find hope. I have found it useful to engage routinely in the process of unravelling once-entrenched ideologies in my own life. By participating in this deconstructive work, I have gained critical lenses with which to view the world around me, a process that reached new heights through my experience in the Walls to Bridges class.

Throughout my studies, I took part in community-based experiential learning opportunities in Central America and the Caribbean, and at social service agencies in Canada. I recognized the benefit and dynamic learning that takes place when the walls of a classroom are toppled and communities and real-life struggles become the context in which you "take notes." It is in these settings where textbooks and journal articles fade away and the most important lessons in one's life are articulated through action and interaction in the real world. These learning opportunities were tempered, however, with continual critical reflection on the impact of my white privilege, neocolonialism, globalization, trade policies, capitalism, and on how my own choices contribute daily to oppression both locally and globally.

Despite this prior reflection and engagement with community-based learning models, none have moved me the as much as Walls to Bridges. Many different facets of my mind and heart were invited to be present and engaged in this classroom space. There are a number of pedagogical values and practices that create the dynamic learning space of a Walls to Bridges classroom. From the very first class, students sit in a circle and are invited to enter into a "circle of trust" where they may speak their truth from their own emotional and intellectual centre to the centre of the class, or as Palmer (2004) describes, "to the receptive heart of the communal space" (p. 118). This process requires listening to each other rather than focusing on proving a point. In addition to trusting each other, we are also asked to trust the process. While students and instructors may have preconceived notions about how class "should go" and the 
agenda may be set, we learn the importance of refraining from pushing through important discussions for the sake of accomplishing a lesson plan. The creation of safety and choices is another foundational value in the classroom. This means that students and the facilitator work to distribute power among all circle members in an effort to learn collaboratively rather than competitively (Walls to Bridges Collective, 2015). In this space of intentional power redistribution, the students teach one another and are continually working to uphold a safe space by staying responsive to issues of power, privilege, and oppression present in the classroom (Walls to Bridges Collective, 2015). By allowing students to engage with their physical, mental, spiritual, and emotional identities, Walls to Bridges fosters collaborative learning with one's whole self. This experience of shared vulnerability, responsibility, growth, and respect within a classroom was new to me, and it demonstrated an alternative way to conduct formal education.

What emerged for me was a critical examination of what exactly "education" is. In my experience, the Walls to Bridges model is somewhat of a novelty within academia, and so I was compelled to ask questions about why this type of learning model and facilitation style is not more widely available for students in post-secondary education. Though I was in my sixth year of university education, I realized I had never critically reflected on the nature of institutionalized education and the power dynamics and complexities at play before taking this class.

After reading and researching some of the challenges facing today's universities, as well as reflecting upon my own experience in this setting for many years, a number of issues became unveiled to me. Within modern day educational institutions, there exists a complex dynamic of competing interests. Universities have dual roles of generating and securing profit through commodification of education and fostering higher learning for the next generation. These roles, at times, become muddied through increasing privatization, corporate sponsorships, and pressure for both students and faculty to produce marketable outputs and achievements that are in line with capitalistic values (Paralta, 2015). In the competitive and rigid environment of 300-person classrooms, students must prove their ability to outshine their peers in order to be successful. Many humans do not flourish to their full potential within these high pressure environments, but adapt themselves to "function" in the most "productive" way possible, making them prime candidates for obedient participation rather than critical thinking (Paralta, 2015).

Universities have become dependent on corporate donors and private investors to maintain financial viability (Schrecker, 2012). Faculty members may obtain corporate funding for their research, but such funding has the potential to place restrictions on research and can be withdrawn if the research is not deemed remunerative (Schrecker, 2012). If profit rather than discovery becomes the motivating factor for scientific inquiry, then academic freedom is in jeopardy (Schrecker, 2012). Schools have been "bought" by corporate interests that pay the struggling education sector large sums to advertise on school property, during school time, while infiltrating educational materials with biased information that pushes an economic 
agenda (Peralta, 2015; Schrecker, 2012). ${ }^{2}$

An eerie parallel may be drawn when comparing the imposition of external force within modern-day educational institutions to modern-day prisons. As Foucault (1977) describes, carceral punishment has shifted from being applied to the body and is often now applied to the soul. Similarly, while no physical harm is used to control students' or faculty members' ideas, there is an element of the "soul" which is inhibited and tamed within the context of corporate interests, rubrics, grades, and competition for funding, acceptance, and scholarships. If one "colours outside of the lines," there may be adverse consequences, such as failing marks, a decrease in research funding, or an increase in workload (Schrecker, 2012). The lines between the market and educational space have been blurred.

Certainly, there are consequences for the corporatization and commercialization of our spaces of learning. Peralta (2015) argues that the corporate university teaches students to be consumers rather than citizens, which in turn encourages unquestioning attitudes towards inequities and social disparities. As schools compete for bodies to fill classrooms so that tuition can float the budget, students are increasingly viewed as "customers that [have] to be wooed rather than minds that [have] to be expanded” (Schrecker, 2012, p. 43). The aligning of corporate and educational values is paradoxical: where the first seeks to perpetuate consumptive patterns, the other (in theory) encourages free thinking and fosters democratic participation. In this teetering balance, where educational institutions are caught between profit motives and platforms for critical voices, there are complex barriers and issues facing today's students.

Mainstream educational institutions fail to recognize and represent the diversity, uniqueness, and creativity of students who are pumped in and out of the machine yearly. Educational curricula, "standards," and structures are determined by a narrow cross section of humanity, which leaves many students and faculty in the margins. The under-representation of women and people of colour within faculty and administrative positions in universities in Canada and the United States further marginalizes students who do not see their own identities reflected in their professors or in those overseeing their institution (Mandhane, 2016). In 2014, 84\% of full-time professors in universities in the United States were white: $58 \%$ were white males and $26 \%$ white females. Only 4\% were black, 3\% Hispanic, $8 \%$ Asian/Pacific Islander, and less than 1\% were American Indian/Alaska Natives and of inter-racial descent (IES, 2014 as cited in Hamer, 2015). In Canada, 83\% of university professors in 2006 were white and 67\% male, while Indigenous people made up only $2.1 \%$ of the professoriate, and black Canadians only $1.6 \%$, with visible minority professors experiencing a $10 \%$ earnings gap with non-minority professors (CAUT Education Review, 2010).

If education is structured and designed by the ruling class and largely for the ruling class, then imagine the difficulties someone who is not a part of the ruling class may face in gaining entry to educational institutions, and meeting the standards that have often been set without

\footnotetext{
2 The implications and dangers of corporatization are also important to consider in relation to the funding of communityengaged learning programs on campus, something that may be of growing concern in this era of increasing austerity and government cut-backs for education. See Aujla and Hamm, this issue, for information on the funding of service-learning programs in Canada.
}

Engaged Scholar Journal: Community-Engaged Research, Teaching and Learning 
cultural, gender, racial, or socio-economic considerations and systemic critique. Gaining entry to university is one challenge, feeling academically supported, having equitable resources, financial assistance, and experiencing a sense of safety and trust with peers and faculty members is another serious set of issues faced (Hamer, 2015). It is necessary for educational institutions to recognize that the experiences of a person of colour and a white person on campus may be very different. Racism permeates many North American university campuses, often insidiously through the minimization of incidents of explicit racism, the denial of racial discrimination on campus, and the reification of dominant assumptions about the cultural and academic deficiencies of students of colour (Bonilla-Silva \& Dietrick, 2011; Mandhane, 2016).

Reynolds (2008) describes poor women of colour as the principal victims of this deficient and failing system. Economic and educational policies not only restrict these women from full participation in educational systems, but in fact push them into criminalized behaviour "as a means of survival" (p. 72). Today, many women who are incarcerated have been affected by poverty, marginalization, and mental health challenges, and the vast majority have experienced violent pasts through either physical or sexual abuse (Van Den Bergh et al., 2011). Indigenous people, particularly Indigenous women, are consistently the most over-represented population in Canada's prisons (Perreault, 2009). While Indigenous people account for $4 \%$ of the Canadian population, they make up $20 \%$ of the incarcerated population (Status of Women Canada, 2012; Wesley Group, 2012). Even more staggering is that in 2010, Indigenous women accounted for $32.6 \%$ of the total population of incarcerated women, meaning that one in three federally incarcerated women is Indigenous (Wesley Group, 2012). A very grave picture of the institutional make-up in our country - who is on the "inside" and who is on the "outside" comes to light when we contrast this staggering statistic with the reality that only $7 \%$ of Indigenous women obtained a university degree in 2006, compared to $19 \%$ of non-Indigenous women (Aboriginal Affairs and Northern Development, 2012).

While the Walls to Bridges class has allowed me the opportunity to question the very nature of institutionalized education, I find myself in a quandary. It is within the very context of a Masters degree in the institutionalized educational setting of Wilfred Laurier University that I have been able to partake in Walls to Bridges and have had the opportunity to analyze critically the nature of educational spaces. This experience has revealed to me the depth of my own privilege. I recognize the hypocrisy of being critical of the exclusive nature of education, while writing this paper with esoteric academic language that further distances me from the type of accessible learning I am calling for. As Pollack and Eldridge (2015) discuss, these revelations demonstrate my need for continued reflexivity, a willingness to asses my power and privilege critically, and to cultivate humility by accepting that my academic way of knowing is not the only way of knowing. Though I have reaped benefits, opportunities, and privileges through my participation in the very system I am critiquing, I continue to wrestle with the dominant hegemony within which the system operates and seek ways to humbly navigate it with an anti-oppressive framework.

Having an educational experience that fosters inter-dependence, cultural competency, critical thinking about systemic issues, collaboration, and connection is incredibly important. 
This type of education lays the foundation for students to realize and assess their own positionality and what it means to be a global citizen and a community member. The focus of education should be shifted from forging "productive" members of a capitalist society to developing community collaboration and compassion. Education should be a space where individual talents, creativity, and abilities are celebrated within the context of strengthening the collective. Within these types of environments, where many viewpoints are shared, mutual understanding and deep learning is fostered, and the foundation of a more socially conscious world is built.

The space that was held for Walls to Bridges embodied these ideas. The classroom was alive and connected. It was a place of openness, of looking into one another's faces and presenting our personal truths. Students were given the opportunity to take responsibility for their class, to determine collectively the guidelines for how all class participants would act together to create a safe space. Class each week started with an opening activity, often initiated by one of the students, which invited participants to become present and available for learning. Experiential and small-group activities were used to promote deeper thinking, creative communication, and the opportunity to express ideas without intimidation from a large group.

Such activities created space for getting to know one another, allowing bridges of understanding to be built between incarcerated students and non-incarcerated students. One example of this transformative learning was when the class facilitator invited us, in small groups, to construct a tableaux - a still, live image co-constructed by all group members using their physical selves to represent a message or topic (Walls to Bridges Collective, 2015). The topic of this particular tableaux was the overrepresentation of women of colour in prison. To depict this theme, my small group, which consisted of incarcerated and non-incarcerated students, decided to create a tableaux with all of the group members lining up in order of the shade of their skin. When presenting our tableaux to the rest of the class, we stood in silence and waited while our classmates began to realize that we were embodying the statistics we had studied on the criminalization of people of colour. We stood there in a racial line-up, which came to life in the lived space of our classroom, a room within a federal prison, where the majority of incarcerated women were women of colour and the majority of non-incarcerated women were white. The emotional impact of this activity was powerful and many students in the class needed time to debrief and discuss what they had experienced. For some students, including myself, this was the first time the research we were studying came alive in a tangible manifestation; it was a moment of transformative learning.

Because the class took place in the physical space of a federal prison, where structural injustice is apparent everywhere, I felt a heightened imperative to critique this injustice. The critical theories discussed in various articles took on new meaning when I began experiencing the concepts studied (Pollack, 2014). The context of the class is crucial as it defies the "safe" distance from which academics so often profess ideas, creating engagement with the very systems and structures being studied (Pollack, 2014). In this way, (in)justice systems move from being studied at a distance, with knowledge coming from the powerful and the privileged, 
to being revealed through exploration with and between marginalized people and through their lived realities (Pollack, 2014). Every voice matters, every person's truth is allowed to exist safely within the circle. Students and facilitator were invited to participate with their whole selves: each individual's social location and intersecting identities were not ignored, but rather acknowledged as contributing to their own personal experience of power and oppression (Walls to Bridges Collective, 2015). Learning is fostered through the interaction of these varying lived experiences and the forming of connections between individuals who may previously have seen themselves as worlds apart.

Circle pedagogy is central to this process. In the Walls to Bridges classroom, students sit in a circle and each participant is provided the space to speak from their various experiences, feelings, and knowledge without interruption or being challenged, while reflecting on what motivates their ideas and responses to course material (Pollack, 2014). Modelled after Parker Palmer's (2004) "Circle of Trust," this process calls participants to "speak our own truth; we listen receptively to the truth of others; we ask each other to be honest, open questions instead of giving counsel; and we offer each other the healing and empowering gifts of silence and laughter" (p. 116). Circle pedagogy is rooted in the belief that everyone has an inner teacher of value and their own truths to be contributed to the circle. This approach provides an alternative to the notion of the teacher as the only expert with the authority to "advise," correct, challenge, and "set students straight" (Palmer, 2004). Professors act as facilitators rather than lecturers, creating activities that do more than just stimulate intellect; they also foster relationships among all students. Calling for a redistribution of educational power, this type of bottom-up classroom holds that the voices and hearts of every person within a circle or classroom bear the same significance and legitimacy. It is a relocation of power from the hands of a few to the hearts of many.

Walls to Bridges is not about right answers or how neatly one can fit into educational expectations; it is about authentic answers, speaking from one's heart and experiences, and being together in solidarity, connection, and honesty. The class embodies the South African philosophy of Ubuntu, loosely translated as "I am because we are." In this space of ingenuity, creativity, resistance, transformation, connection, and hope, critical parts of me came together to create something meaningful. The nature of the Walls to Bridges space fostered a transcendent educational experience. bell hooks (as cited in Musial, 2012) describes this as "an ecstatic experience" (p. 226). She states, "When we bring conscious mindfulness to work in the classroom we often have an ecstatic experience... at times like this I feel myself to be in the presence of the sacred ... It is the collective learning taking place that produces the sensation of communal spirit" (p. 226). Many students shared the feeling that what had unfolded in the space was sacred and expressed having been deeply moved. Rather than devouring academic information in order to vomit it forth into a "brilliant" paper or rigidly structured test, the facts of which I often struggled to retain, I was called in the Walls to Bridges classroom to contribute parts of my authentic self to the community of the circle without the intention of obtaining the highest grade possible.

As Musial (2012) describes, too much emphasis has been placed on learning that delineates 
between the mind and the heart. bell hook's idea of engaged pedagogy resonates a great deal with me, for learning which requires a mind-body-spirit connection is transformative and lasting (Musial, 2012). Within this context, where empowering students is at the forefront of a teacher's concerns, teachers themselves must also be continually engaged in their own self growth and healing (Musial, 2012). When teachers are engaged in this work, they are more able to hold the space of self-healing and transformation for their students. The rigid space of the high-pressured, corporatized, intellect-oriented classroom needs to be transformed into a space where we acknowledge one another as emotional and spiritual beings as well as intellectuals and academics. In order to do this, a feminist heart-centred approach may be used to encourage students' self-reflection and personal growth while reducing classroom competition (Musial, 2012). Learning and education can exist in heart-centred spaces that embrace everything students and teachers bring to the space, not just their brains (Musial, 2012).

We have the power to call for change in our educational system and pedagogical approaches. Rather than fitting marginalized individuals into an educational paradigm and structure which inherently oppresses them, I suggest we address the structure itself. The first step is to open up the dominant conversations about education to include the voices of those who are subject to a system within which they may face many barriers. This would require having difficult conversations about patriarchy, classism, racism, and discrimination, rather than couching these crucial conversations in the innocuous language of "diversity and inclusion' policies (Mandhane, 2016). More work must be done to discuss and assess how the current system functions and/or dysfunctions, and these discussions must include and center the voices of those with lived experiences as marginalized students and faculty (Mandhane, 2016). These conversations must not be held privately in the chambers of ivory towers, but rather in public and accessible spaces, inviting many voices into the conversation. It must be determined whether education exists for people or for profit.

In order to expand alternative approaches to learning, or rather promote the pursuit of "unlearning" dominant educational paradigms, classes like Walls to Bridges should be brought in from the margins of educational spaces into the centre. This re-centring must be done carefully and with constant reflection in order not to water down the approach or contaminate the marginal with the mainstream. Instead, it is time that the mainstream begins to recognize that people are inherently more alive, powerful, capable, and brilliant than much of institutionalized education allows them to demonstrate. Educational spaces of radical openness, collaboration, trust, and diversity must not be seen as threats, but rather as opportunities for deep learning, for becoming more completely interconnected, and more successful as human beings. Such spaces have the power to transform classrooms and communities by planting seeds of mutual respect, empowerment, and hope in the minds of a new generation. I know, because these transformational seeds have now been planted within me, and I am excitedly forging a path of growth that honours what this experience has taught me. 


\begin{abstract}
About the Author:
Anna Sferrazza is an MSW graduate from Wilfrid Laurier University. She has been passionately involved in a broad spectrum of community organizations over the past decade. The commonality underlying her experiences has been a desire to support individuals with creativity, profound respect, and the utmost promotion of human dignity. Email: anna.r.sferrazza@ gmail.com
\end{abstract}

\title{
References
}

Aboriginal Affairs and Northern Development. (2012). Aboriginal women in Canada.

Aronowitz, S. (2000). The Knowledge Factory: Dismantling the corporate university and creating true higher learning. Boston, MA: Beacon Press.

Bonilla-Silva, E., \& Dietrich, D. (2011). The sweet enchantment of color-blind racism in obamerica. The Annals of the American Academy of Political and Social Science, 634, 190-206.

Canadian Association of University Teachers, (2010). The changing academy: A portrait of Canada's university teachers. Volume 12.

Fine, M., Torre, M. E., Boudin, K., Bowen, I., Clark, J., Hylton, D., . . Upegui, D. (2012). Changing minds: a participatory action research project on college in prison. In R. Solinger \& R.

Sharitz (Eds.), Interrupted life: Experiences of incarcerated women in the United States (pp. 188-195). Berkeley, CA: University of California.

Foucault, M. (1977). Chapter one. In Discipline and punish: The birth of the prison (pp. 3-31). New York, NY: Pantheon Books.

Hamer, J. F., \& Lang, C. (2015). Race, structural violence, and the neoliberal university: The challenges of inhabitation. Critical Sociology, 41, 897-912.

Institute of Education Sciences (IES). (2014). Race/ethnicity of college faculty. Fast Facts, National Center for Education Statistics.

Mandhane, R. (2016). Proceedings from Ontario Human Rights Commission: E(race)r summit on race and racism on

Canadian University campuses.

Musial, J. (2012). Engaged pedagogy in the feminist classroom and yoga studio. Feminist teacher, 21, 212-228.

Palmer, P. (2004). Chapter seven: Deep speaks to deep: learning to speak and listen. In $A$ bidden wholeness: the journey toward an undivided life (pp. 113-128). San Francisco, CA: Josseu-Bass.

Perreault, S. (2009). The incarceration of Aboriginal people in adult correctional services. Statistics Canada.

Peralta, A. K. (2015). Corporate-school partnerships and neoliberal influences on students as future participants in the labor market. Brigham Young University Education \& Law Journal, 1, 297-321.

Pollack, S. (2014). Rattling assumptions and building bridges: Community-engaged education and action in a woman's prison. In G. Balfour and E. Comack (Eds.), Criminalizing women: Gender and (in)justice in neoliberal times (pp. 290-302). Halifax, NS: Fernwood Publishing Company Ltd. 
Pollack, S., \& Eldridge, T (2015). Complicity and redemption: Beyond the insider/outsider research dichotomy. Social Justice, 42, 132-145.

Reynolds, M. (2008). The war on drugs, prison building, and globalization: Catalysts for the global incarceration of women. Feminist Formations, 20(2), 72-94.

Schrecker, E. (2012). Academic freedom in the corporate university. The Radical Teacher, 93, 38-45. Status of Women Canada. (2012). Women in Canada at a glance: Statistical highlights.

Van Den Bergh, B. J., Gatherer, A., Fraser, A., \& Moller, L. (2011). Imprisonment and women's health: Concerns about gender sensitivity, human rights and public health. Bulletin World Health Organization, 89, 689-694.

Walls to Bridges Collective (2015). Walls to bridges facilitator training manual.

Wesley, M. (2012). Marginalized: The Aboriginal women's experience in federal corrections. Public Safety Canada. 